\title{
Antibacterial therapeutics for the treatment of chytrid infection in amphibians: Columbus's egg?
}

\author{
Mariska Muijsers ${ }^{1}$, An Martel ${ }^{1}$, Pascale Van Rooij ${ }^{1}$, Kris Baert ${ }^{2}$, Griet Vercauteren ${ }^{1}$, Richard Ducatelle ${ }^{1}$, \\ Patrick De Backer ${ }^{3}$, Francis Vercammen ${ }^{4}$, Freddy Haesebrouck ${ }^{1}$ and Frank Pasmans ${ }^{1 *}$
}

\begin{abstract}
Background: The establishment of safe and effective protocols to treat chytridiomycosis in amphibians is urgently required. In this study, the usefulness of antibacterial agents to clear chytridiomycosis from infected amphibians was evaluated.

Results: Florfenicol, sulfamethoxazole, sulfadiazine and the combination of trimethoprim and sulfonamides were active in vitro against cultures of five Batrachochytrium dendrobatidis strains containing sporangia and zoospores, with minimum inhibitory concentrations (MIC) of $0.5-1.0 \mu \mathrm{g} / \mathrm{ml}$ for florfenicol and $8.0 \mu \mathrm{g} / \mathrm{ml}$ for the sulfonamides. Trimethoprim was not capable of inhibiting growth but, combined with sulfonamides, reduced the time to visible growth inhibition by the sulfonamides. Growth inhibition of $B$. dendrobatidis was not observed after exposure to clindamycin, doxycycline, enrofloxacin, paromomycin, polymyxin $E$ and tylosin. Cultures of sporangia and zoospores of B. dendrobatidis strains JEL423 and IA042 were killed completely after 14 days of exposure to $100 \mu \mathrm{g} / \mathrm{ml}$ florfenicol or $16 \mu \mathrm{g} / \mathrm{ml}$ trimethoprim combined with $80 \mu \mathrm{g} / \mathrm{ml}$ sulfadiazine. These concentrations were, however, not capable of efficiently killing zoospores within 4 days after exposure as assessed using flow cytometry. Florfenicol concentrations remained stable in a bathing solution during a ten day period. Exposure of Discoglossus scovazzi tadpoles for ten days to $100 \mu \mathrm{g} / \mathrm{ml}$ but not to $10 \mu \mathrm{g}$ florfenicol $/ \mathrm{ml}$ water resulted in toxicity. In an in vivo trial, post metamorphic Alytes muletensis, experimentally inoculated with $B$. dendrobatidis, were treated topically with a solution containing $10 \mu \mathrm{g} / \mathrm{ml}$ of florfenicol during 14 days. Although a significant reduction of the $B$. dendrobatidis load was obtained, none of the treated animals cleared the infection.
\end{abstract}

Conclusions: We thus conclude that, despite marked anti B. dendrobatidis activity in vitro, the florfenicol treatment used is not capable of eliminating $B$. dendrobatidis infections from amphibians.

\section{Background}

Amphibian medicine is a relatively young veterinary discipline and, so far, few studies have been carried out in order to develop evidence-based treatment protocols. Current treatment protocols against amphibian pathogens are most often based on empirical evidence and lack well supported scientific evidence. This major gap in veterinary science has garnered attention with the global emergence of the deadly fungal infection chytridiomycosis, a disease linked to mass mortalities and extinctions of amphibian

\footnotetext{
* Correspondence: frank.pasmans@Ugent.be

'Department of Pathology, Bacteriology and Avian Diseases, Faculty of Veterinary Medicine, Ghent University, Salisburylaan 133, Merelbeke B-9820, Belgium

Full list of author information is available at the end of the article
}

species during the last decades [1,2]. The causative agent, Batrachochytrium dendrobatidis, is an aquatic pathogen with two life stages: a uniflagellated motile zoospore and an immotile reproductive zoosporangium [3]. In infected amphibians, $B$. dendrobatidis zoosporangia are found in the upper layers of the epidermis, causing hyperkeratosis and excessive shedding of the skin [1]. In more severe cases, $B$. dendrobatidis' capacity to disrupt normal regulatory skin functions (e.g. exchange of respiratory gases, water and electrolytes) causes electrolyte depletion and osmotic imbalance inducing clinical signs, like dehydration and anorexia, and death $[4,5]$.

Controlling this disease and stabilizing populations of endangered amphibian species in captivity and in the wild has become a priority in amphibian conservation. The importance of clinical trials to develop an effective

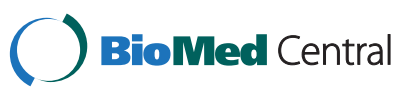


Table 1 Strains of $B$. dendrobatidis used in this study

\begin{tabular}{ll}
\hline Strain & Origin \\
\hline JEL197 & Dendrobatus azureus \\
\hline JEL277 & Ambystoma tigrinum \\
\hline JEL310 & Smilisca phaeota \\
\hline JEL423 & Lithobates catesbeianus \\
\hline IA042 & Alytes obstreticans \\
\hline
\end{tabular}

and safe treatment for chytridiomycosis has recently been put forward by Berger et al. [6]. At this moment minimum inhibitory concentrations in vitro against B. dendrobatidis have been determined for 10 antifungal agents: benzalkonium chloride $(0.78 \mu \mathrm{g} / \mathrm{ml})$, povidone iodine $(312.5 \mu \mathrm{g} / \mathrm{ml})$, amphotericin B $(3.125 \mu \mathrm{g} / \mathrm{ml})$, fluconazole $(1.56 \mu \mathrm{g} / \mathrm{ml})$, itraconazole $(1.56 \mu \mathrm{g} / \mathrm{ml})$, enilconazole $(1.56 \mu \mathrm{g} / \mathrm{ml})$, mercurochrome $(6.25 \mu \mathrm{g} / \mathrm{ml})$, sodium chloride $(12.5 \mathrm{mg} / \mathrm{ml})$, voriconazole $(0.0125 \mu \mathrm{g} / \mathrm{ml})$ and caspofungin $(16 \mu \mathrm{g} / \mathrm{ml})$ [7-9]. The use of these agents on a large scale in amphibians is hindered mainly due to toxic side effects, high prices or in vivo failure of activity [7-10]. Benzalkonium chloride, amphotericin B and fluconazole failed to clear $B$. dendrobatidis in vivo $[7,8]$. Moreover, amphotericin B was acutely toxic to Alytes muletensis tadpoles [8]. Formaldehyde and malachite green, even though found useful by Parker et al. [11], are extremely toxic, especially to tadpoles [12].

At present, especially itraconazole and voriconazole are antifungal agents of choice $[8,10]$. However, the treatment schedule of itraconazole is laborious and depigmentation of treated tadpoles has been observed [10]. Voriconazole, while apparently safe and effective, is quite expensive, the intravenous formulation hard to obtain and moreover, it is considered vital for the treatment of human patients with e.g. aspergillosis and therefore not the drug of choice for high scale use in veterinary medicine [8].

In 2009, Bishop et al. discovered the efficacy of chloramphenicol in the treatment of chytridiomycosis [13]. However, chloramphenicol is known to cause bone marrow toxicity in humans [14] and can also induce leukemia in amphibians [15]. The discovery that an antibacterial compound can be effective against $B$. dendrobatidis offers new opportunities for the development of a treatment protocol.

The aim of this study was to evaluate the usefulness of 10 antimicrobial agents for the treatment of chytridiomycosis. The minimal inhibitory concentrations were determined to make a first selection of in vitro efficacy. Florfenicol and trimethoprim sulfadiazine were further selected to determine the minimum fungicidal concentration and the time needed to kill the fungus in vitro. Finally, for florfenicol, stability, toxicity and treatment efficacy in midwife toads (Alytes muletensis), experimentally infected with $B$. dendrobatidis, were determined.

\section{Methods}

Strains and culture conditions

Five B. dendrobatidis strains, kindly provided by Dr. J. Longcore, Dr. T. Garner and Dr. M. Fisher, were used in this study (Table 1). The strains were grown in TGhL broth (16 $\mathrm{g}$ tryptone $+2 \mathrm{~g}$ hydrolysed gelatin $+4 \mathrm{~g}$ lactose in $1 \mathrm{l}$ distilled water) in $25 \mathrm{~cm}^{2}$ cell culture flasks at $20^{\circ} \mathrm{C}$ for 5 days. For the collection of zoospores for the experimental inoculation, one $\mathrm{ml}$ of a 5 day old broth culture was inoculated on TGhL agar (16 g tryptone $+2 \mathrm{~g}$ hydrolysed gelatin $+4 \mathrm{~g}$ lactose $+10 \mathrm{~g}$ agar in $1 \mathrm{l}$ distilled water) and incubated for 5 to 7 days at $20^{\circ} \mathrm{C}$. Zoospores were collected by flooding the agar with $2 \mathrm{ml}$ of distilled water and collecting the supernatant.

\section{Determination of minimum inhibitory concentrations of antimicrobial agents}

The minimum inhibitory concentration (MIC) of antimicrobial agents, each belonging to a different pharmacological group, for the $B$. dendrobatidis isolates were determined using a macrodilution method in 24 well plates following the method described by Martel et al. (2010) [8]. To each well, $200 \mu \mathrm{l}$ of TGhL broth containing various concentrations of clindamycin (SigmaAlderich Chemi Gmbh, Steinheim, Germany), doxycyclin (Sigma-Alderich Chemi Gmbh, Steinheim, Germany), enrofloxacin (Bayer B.V., Diegem, Belgium), florfenicol (20\%), paromomycin (Sigma-Alderich Chemi Gmbh, Steinheim, Germany), polymyxin E (V.M.D., Arendonk, Belgium), sulfamethoxazole (Sigma-Alderich Chemi Gmbh, Steinheim, Germany), trimethoprim (SigmaAlderich Chemi Gmbh, Steinheim, Germany), a combination of trimethoprim and sulfamethoxazole in a ratio of $1: 5$, a commercially available combination of trimethoprim and sulfadiazine in a ratio of 1:5 (trimazin 30\%, Kela laboratoria nv, Hoogstraten, Belgium) or tylosin (Sigma-Alderich Chemi Gmbh, Steinheim, Germany), were added to $200 \mu \mathrm{l}$ of a 3 to 4 day old growing culture containing approximately $10^{5} \mathrm{~B}$. dendrobatidis organisms consisting of a mixture of zoospores and zoosporangia. Addition of $1600 \mu \mathrm{l}$ TGhL broth to each well, resulted in final assay antimicrobial concentrations of 8 , $4,2,1,0.5,0.25,0.125,0.063,0.031$ and $0.016 \mu \mathrm{g} / \mathrm{ml}$. In the two combinations of trimethoprim and sulfonamides this dilution resulted in final concentrations of trimethoprim/sulfonamide of $1.6 / 8,0.8 / 4,0.4 / 2,0.2 / 1$, $0.1 / 0.5,0.05 / 0.25,0.025 / 0.125,0.013 / 0.063,0.0063 / 0.031$ and $0.0031 / 0.016 \mu \mathrm{g} / \mathrm{ml}$. The $B$. dendrobatidis cultures were examined for visible growth at $1,2,4,6,8,10$ and 14 days of incubation. Growth was compared to wells, containing $B$. dendrobatidis in TGhL broth without antimicrobial compound and was defined both as microscopically visible development of zoospores to sporangia, 
and a visible increase in the number of fungal organisms. The MIC value was determined as the lowest drug concentration at which no growth of the $B$. dendrobatidis strain was visible after 14 days of incubation at $20^{\circ} \mathrm{C}$ using inverted microscopic examination. The experiment was carried out three times in triplicate for two strains (IA042 and JEL423). If growth inhibition was noticed for a given compound, the experiment was repeated for this compound for all five B. dendrobatidis strains (IA042, JEL197, JEL277, JEL310 and JEL423).

\section{Determination of the time to $100 \%$ killing of}

$B$. dendrobatidis by florfenicol and trimethoprim-sulfadiazin Based on the results of the MIC determination, florfenicol and the commercially available combination of trimethorpim and sulfadiazine were selected for further testing. The time to $100 \%$ killing of $B$. dendrobatidis by florfenicol and trimethoprim - sulfadiazine (TMP-S) was assessed in 24 well plates as described previously [8]. For florfenicol, the strains IA042 and JEL423 were exposed to concentrations equal to the minimal inhibitory concentration $(1 \mu \mathrm{g} / \mathrm{ml}), 10$ times the minimal inhibitory concentration $(10 \mu \mathrm{g} / \mathrm{ml})$ and 100 times the minimal inhibitory concentration $(100 \mu \mathrm{g} / \mathrm{ml})$ during 1, 2, 4, 6, 8, 10 and 14 days. For TMP-S, the 2 strains were exposed to concentrations of $1.6,3.2,8$ and $16 \mu \mathrm{g} / \mathrm{ml}$ trimethoprim in combination with $8 \mu \mathrm{g} / \mathrm{ml}, 16 \mu \mathrm{g} / \mathrm{ml}, 40 \mu \mathrm{g} / \mathrm{ml}$ and $80 \mu \mathrm{g} / \mathrm{ml}$ of sulfadiazine corresponding to $1,2,5$ and 10 times the minimal inhibitory concentration of sulfadiazine respectively, during 1, 2, 4, 6, 8, 10 and 14 days. Growth in the wells was compared to that in untreated control wells, allowing estimation of the percentage of growth reduction. After the exposure time, the medium was replaced by fresh TGhL broth without antimicrobials and the plates were further incubated for 14 days at $20^{\circ} \mathrm{C}$. The time to $100 \%$ killing at a given antimicrobial concentration was defined as the earliest time point of medium replacement at which no growth of the strain was observed after 14 days of incubation at $20^{\circ} \mathrm{C}$. All experiments were carried out twice in triplicate.

\section{Killing capacity of florfenicol and trimethoprim - sulfadiazine towards $B$. dendrobatidis zoospores}

To determine the killing capacity of florfenicol and trimethoprim sulfadiazine towards $B$. dendrobatidis zoospores of strain IA042, the uptake of propidium iodide (PI) after exposure to florfenicol or trimethoprim sulfadiazine was assessed using flow cytometry as described previously [8]. A suspension containing approximately $10^{6}$ zoospores $/ \mathrm{ml}$ distilled water was exposed to either $1 \mu \mathrm{g} / \mathrm{ml}, 10 \mu \mathrm{g} / \mathrm{ml}$ or $100 \mu \mathrm{g} / \mathrm{ml}$ florfenicol or $1.6,3.2$, 8 or $16 \mu \mathrm{g} / \mathrm{ml}$ trimethoprim in combination with $8 \mu \mathrm{g} / \mathrm{ml}, 16 \mu \mathrm{g} / \mathrm{ml}, 40 \mu \mathrm{g} / \mathrm{ml}$ or $80 \mu \mathrm{g} / \mathrm{ml}$ sulfadiazine, and incubated for 1,2 and 4 days at $20^{\circ} \mathrm{C}$. The suspensions were transferred into Falcon tubes and PI was added to achieve a final concentration of $2 \mu \mathrm{g} / \mathrm{ml} \mathrm{PI}$. After incubation for 5 minutes at room temperature in the dark, the samples were analyzed using a FACSCanto flowcytometry system (Becton Dickinson Biosciences, Erembodegem, Belgium). Analyses were performed using FACSDiva software v5.0.1 (Becton Dickinson Biosciences). Vital zoospores were used to set light scatter gates for zoospore characteristics and zoospores killed with heat were used to set gates for PI positivity.

\section{Florfenicol stability in water}

Based on the results obtained, florfenicol was selected for further experiments. To determine whether florfenicol treatment should include daily replacement of the bathing solution, the concentration of florfenicol was measured for 10 days in $20^{\circ} \mathrm{C}$ bathing solution containing either $10 \mu \mathrm{g} / \mathrm{ml}$ or $100 \mu \mathrm{g} / \mathrm{ml}$ florfenicol. Water concentrations of florfenicol were determined using a HPLC method with ultraviolet (UV) detection. The samples were analysed after appropriate dilution on a Thermo Separations Product (TSP, Fremont, CA, USA) HPLCsystem using a Spectrasystem gradient pump, a Model AS 3000 autosampler and a Spectrafocus diode array detector set at $223 \mathrm{~nm}$. A reversed-phase $C_{18}$ column (100 x 4.6 mm ID, $5 \mu \mathrm{m}$ Nucleosil, Varian, Harbor City, USA) and a guard column of the same type were used. The injection volume was $50 \mu \mathrm{l}$, the flow rate was $0.35 \mathrm{ml} / \mathrm{min}$ and the run time was set at $13 \mathrm{~min}$. The mobile phase consisted of $80 \%$ water and $20 \%$ acetonitrile (VWR, Leuven, Belgium) [16]. All samples were taken in triplicate.

\section{Toxicity of florfenicol for tadpoles}

Fifteen Discoglossus scovazzi tadpoles (Gosner stage 26-30) were individually housed in $600 \mathrm{ml}$ of water at a temperature of $20^{\circ} \mathrm{C}$ in a room with a day-night cycle of $12 \mathrm{~h}: 12 \mathrm{~h}$ and five animals were either exposed for 10 days to $10 \mu \mathrm{g} / \mathrm{ml}$ or $100 \mu \mathrm{g} / \mathrm{ml}$ florfenicol or not exposed to any antimicrobial drug. Animals were fed daily with commercial fish food pellets (Sera $\mathrm{GmbH}$, Heinsberg, Germany) and weights were measured one hour before exposure and on day ten of this experiment. Daily observations for abnormal behavior, pathological signs or death were carried out. At the end of the experiment all animals were humanely euthanized and haematoxylin and eosin staining of paraffin embedded formalin fixed transversal whole body sections were examined for the presence of histological signs of toxicity. Statistical analyses of the results were performed using SPSS 17. This experiment was approved by the ethical committee of the Faculty of Veterinary Medicine, Ghent University. 
Treatment of experimentally infected midwife toads (Alytes muletensis) with florfenicol

\section{B. dendrobatidis strain and growth condition}

For the experimental infection, $B$. dendrobatidis strain IA042, isolated from a dead Alytes obstetricans, was used. The strain was grown on TGhL-agar for 5 days at $20^{\circ} \mathrm{C}$. Subsequently, zoospores were collected by flooding the agar with $2 \mathrm{ml}$ distilled water. Determination of zoospore density in the suspension was assessed using a Bürker counting chamber. The amount of zoospores in the suspension was then adjusted to approximately $10^{7}$ zoospores $/ \mathrm{ml}$.

\section{Experimental animals}

All animal experiments were approved by the ethical committee of the Faculty of Veterinary Medicine (Ghent University). Experiments were performed following all necessary ethical and biosecurity standards. Twelve captive bred $A$. muletensis at approximately 6 months post metamorphosis were used in this experiment. The animals were kept in filter top cages $(32 \times 17 \times 21 \mathrm{~cm})$ lined with moist tissue, containing terracotta flower-pots as shelter and a petri-dish filled with dechlorinated tap water for bathing and were fed fruit flies with calcium supplementation ad libitum. Ambient temperature varied between $16-20^{\circ} \mathrm{C}$ and was monitored using an automatic data logger device (Escort intelligent mini $3.0 \mathrm{~V}$ data recorder, Escort Data Loggers Inc., Buchanan, VA, USA).

\section{Experimental inoculation and treatment}

The animals were inoculated three times with a four day interval by topical inoculation of $0.1 \mathrm{ml}$ of the zoospore suspension per animal. To determine whether the experimental inoculation resulted in infection, samples of the drinking patch and plantar sides of the feet were collected using rayon tipped swabs $(160 \mathrm{C}$, Copan Italia S.p.A., Brescia, Italy) and examined after 1 week for the presence of $B$. dendrobatidis DNA using the $q \mathrm{PCR}$ test described by Boyle et al. [17]. As soon as all animals tested positive for the presence of $B$. dendrobatidis DNA twice with an interval of 1 week, the animals were divided into two groups. The first group of six animals served as untreated positive controls. The second group of six animals was treated daily with florfenicol at a concentration of $10 \mathrm{mg} / \mathrm{l}$ water. The treatment consisted of transferring the frogs to a disinfected container lined with tissue paper and daily spraying of the frogs and the container contents with the respective solution. Rayon tipped swabs were used to collect samples from the pelvic region and toes of all animals from the first day after treatment onwards. These swabs were examined for the presence of $B$. dendrobatidis DNA using the $q \mathrm{PCR}$ method mentioned above.

\section{Results}

B. dendrobatidis is susceptible to florfenicol and sulfonamides

Growth inhibition was observed after exposure to florfenicol or sulfonamides but not clindamycin, doxycyclin, paromomycin, polymyxin-E, trimethoprim solely and tylosin. Florfenicol had the lowest MIC for B. dendrobatidis with three strains (IA042, JEL197 and JEL310) being susceptible to a concentration of $1 \mu \mathrm{g} / \mathrm{ml}$ and two strains (JEL277 and JEL423) to a concentration of $0.5 \mu \mathrm{g} / \mathrm{ml}$. Inhibition of the development of the spo rangia was visible at 4-5 days of exposure to these concentrations. For sulfamethoxazole, marked inhibition of sporangium development of $B$. dendrobatidis-strains IA042 and JEL423 was observed after 3-4 days of expo sure to a concentration of $8 \mu \mathrm{g} / \mathrm{ml}$ but already at 2 days after exposure to $8 \mu \mathrm{g} / \mathrm{ml}$ when combined with $1.6 \mu \mathrm{g} / \mathrm{ml}$ trimethoprim. Visible growth of all 5 strains tested was inhibited by $1.6 \mu \mathrm{g} / \mathrm{ml}$ trimethoprim in combination with $8 \mu \mathrm{g} / \mathrm{ml}$ sulfamethoxazole or sulfadiazine after 2 days of exposure.

\section{Limited fungicidal activity of florfenicol and trimethoprim - sulfadiazine against $B$. dendrobatidis}

Based on the results of the MIC determination, florfenicol and the combination trimethoprim sulfadiazine were selected to evaluate their fungicidal activity. At a concentration of 100 but not at 1 and $10 \mu \mathrm{g} / \mathrm{ml}$ of florfenicol, B. dendrobatidis cultures were completely killed within 14 days of exposure. At $10 \mu \mathrm{g} / \mathrm{ml}$, sporadic viable zoospores were observed. For trimethoprim sulfadiazine, exposure to $16 \mu \mathrm{g} / \mathrm{ml}$ trimethoprim combined with $80 \mu \mathrm{g} / \mathrm{ml}$ sulfadiazine during 14 days was necessary to kill the $B$. dendrobatidis culture completely. Exposure to 3.2 and $8 \mu \mathrm{g} / \mathrm{ml}$ trimethoprim and 16 and $40 \mu \mathrm{g} / \mathrm{ml}$ sulfadiazine resulted in near absence of viable zoospores at 14 days. No significant killing was observed after exposure during 14 days to $1.6 \mu \mathrm{g} / \mathrm{ml}$ of trimethoprim combined with sulfadiazine at $8 \mu \mathrm{g} / \mathrm{ml}$. No differences between the two tested strains (IA042 and JEL423) were observed. Compared to untreated zoospores, zoospores exposed to florfenicol at a concentration of 1,10 or $100 \mu \mathrm{g} / \mathrm{ml}$ were not killed within 4 days, as assessed using flow cytometry. Exposure to trimethoprim sulfadiazine at a concentration of trimethoprim/sulfadiazine of $1.6 / 8 \mu \mathrm{g} / \mathrm{ml}, 3.2 / 16 \mu \mathrm{g} / \mathrm{ml}, 8 / 40 \mu \mathrm{g} / \mathrm{ml}$ or $16 / 80 \mu \mathrm{g} / \mathrm{ml}$ also did not kill zoospores within 4 days.

\section{Florfenicol remains stable during at least 10 days in tank water}

The quantification of the florfenicol concentration in water samples using HPLC showed no decrease of the concentration during the ten day period at both 
Table 2 Means of weights \pm standard deviation at day 1 and day 10 and average weight gain \pm standard deviation of Discoglossus scovazzi tadpoles ( $n=5$ per treatment group) during a ten day treatment experiment

\begin{tabular}{|c|c|c|c|}
\hline \multirow[t]{2}{*}{ Treatment } & \multirow{2}{*}{$\begin{array}{l}\text { Weight } \\
\text { (mg) } \\
\text { day } 1\end{array}$} & \multirow{2}{*}{$\frac{\text { Weight }(\mathrm{mg})}{\text { day } 10}$} & \multirow[t]{2}{*}{ Weight gain (mg) } \\
\hline & & & \\
\hline Florfenicol $10 \mu \mathrm{g} / \mathrm{ml}^{\mathrm{a}}$ & $103 \pm 12$ & $197 \pm 25$ & $93 \pm 24$ \\
\hline Florfenicol $100 \mu \mathrm{g} / \mathrm{ml}^{\mathrm{b}}$ & $115 \pm 28$ & $137 \pm 10$ & $22 \pm 20$ \\
\hline Control $^{a}$ & $87 \pm 20$ & $210 \pm 59$ & $123 \pm 57$ \\
\hline
\end{tabular}

concentrations $(10 \mu \mathrm{g} / \mathrm{ml}$ and $100 \mu \mathrm{g} / \mathrm{ml})$, rendering florfenicol suitable for a single bath treatment.

Exposure of tadpoles to high doses of florfenicol results in decreased weight gain

\section{Clinical observation}

No clinical abnormalities were observed in tadpoles exposed to either $10 \mu \mathrm{g} / \mathrm{ml}$ or $100 \mu \mathrm{g} / \mathrm{ml}$ florfenicol.

\section{Weights}

Table 2 shows the average weights of the tadpoles at days 1 and 10 and the average weight gain during this ten day period. No significant differences were found between the weights of the different groups at the start of this experiment. Using one-way ANOVA and a
Bonferroni test significant differences between means were found for weights at day 10 and mean weight gain between the group treated with $100 \mu \mathrm{g} / \mathrm{ml}$ and the control group. Also, weights at day 10 and mean weight gain significantly differed between the group treated with $100 \mu \mathrm{g} / \mathrm{ml}$ and the group treated with $10 \mu \mathrm{g} / \mathrm{ml}$. No significant differences were found between the weights at day 10 and the mean weight gain between the group treated with $10 \mu \mathrm{g} / \mathrm{ml}$ florfenicol and the control group that did not receive florfenicol treatment. Histopathological examination of the tadpoles revealed the absence of lesions in the negative control animals and mild multifocal vacuolization of epithelial cells in gut and kidneys of the animals exposed to $10 \mu \mathrm{g} / \mathrm{ml}$. In the tadpoles exposed to $100 \mu \mathrm{g} / \mathrm{ml}$, diffuse and marked vacuolization of epithelial cells in the gut with marked apoptosis of enterocytes and mild to moderate vacuolization of the renal tubular cells were present.

Fourteen day treatment with $10 \mu \mathrm{g} / \mathrm{ml}$ florfenicol reduces but does not eliminate $B$. dendrobatidis from

experimentally infected postmetamorphic Alytes muletensis Immediately before the experimental treatment, all animals tested positive on $q$ PCR with an average load of $5,4 \pm 4,4$ B. dendrobatidis genomic equivalents $(\mathrm{GE})$ in

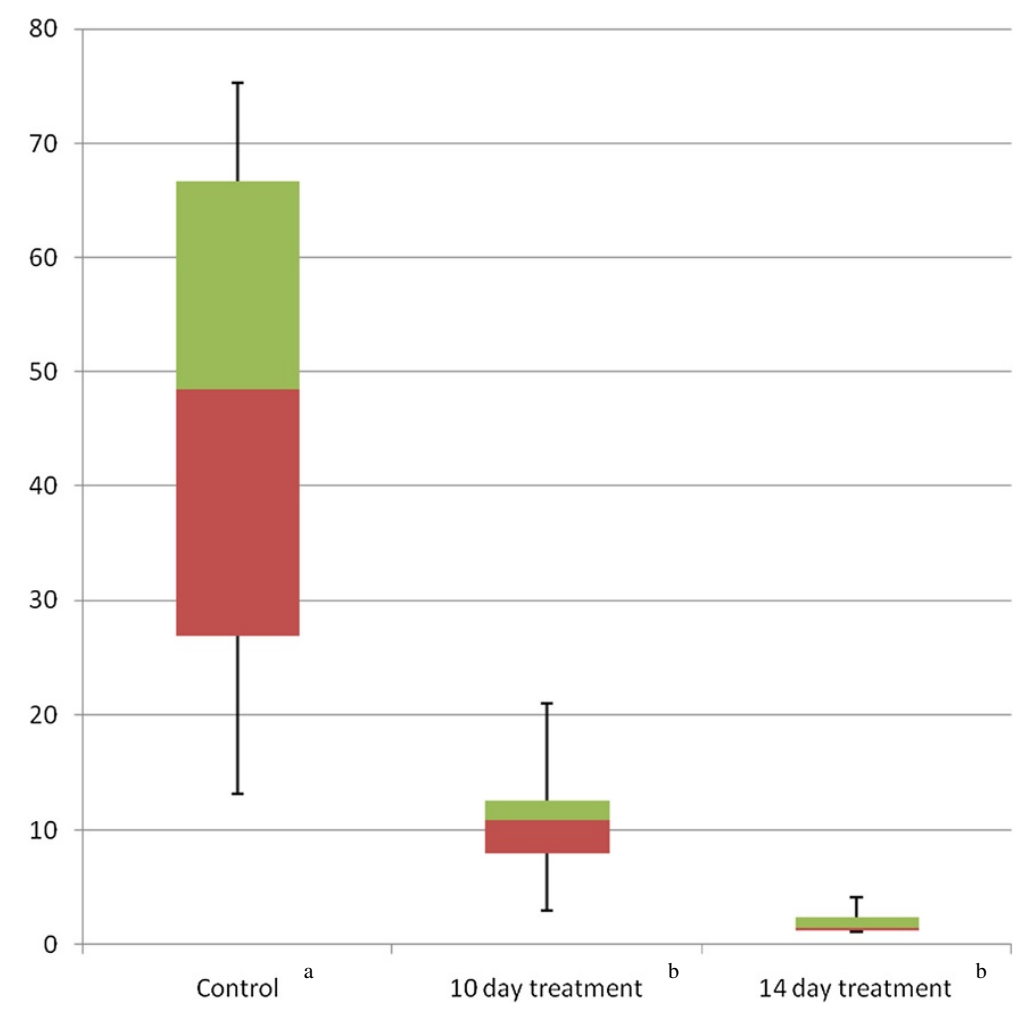

Figure 1 Boxplots of genomic equivalents (GE) of $B$. dendrobatidis in skin swabs from Alytes muletensis that were either not treated (control, determined at the end of the 14 days treatment period) or treated during 10 days or 14 days with florfenicol at a concentration of $10 \mu \mathrm{g} / \mathrm{ml}$. 
Table 3 Mean load of genomic equivalents (GE) \pm standard deviation of $B$. dendrobatidis in skin swabs collected from Alytes muletensis, experimentally inoculated with $B$. dendrobatidis, after a 14 days treatment period with $10 \mu \mathrm{g} / \mathrm{ml}$ florfenicol

\begin{tabular}{llll}
\hline $\begin{array}{l}\text { Days post } \\
\text { treatment }\end{array}$ & $\begin{array}{l}\text { No. of } \\
\text { animals }\end{array}$ & $\begin{array}{l}\text { No. of } \\
\text { positives }\end{array}$ & $\begin{array}{l}\text { Genomic } \\
\text { equivalents }\end{array}$ \\
\hline $\mathbf{1}$ & 6 & 6 & $1.6 \pm 1.5$ \\
\hline $\mathbf{1 0}$ & 6 & 6 & $5.1 \pm 10.3$ \\
\hline $\mathbf{2 4}$ & 5 & 5 & $9.4 \pm 7.1$ \\
\hline
\end{tabular}

skin swabs. After 14 days of treatment, all animals were still positive (Figure 1). The average load of genomic equivalents was lower in the treated than in the untreated animals. The Mann-Whitney $U$ test showed statistically significant differences between both the 10 and 14 day treatment group and the control group $(\mathrm{P}<0.011$ and $\mathrm{P}<0.006$ respectively). No significant difference was found between the 10 and 14 day treatment groups. After treatment termination, increase in the number of GE in the treated frogs was noted (Table 3).

\section{Discussion}

In this study, a range of antimicrobial agents were tested for their in vitro efficacy against $B$. dendrobatidis. Only florfenicol, a chloramphenicol analog, sulfonamides and a combination of trimethoprim and sulfonamides showed in vitro efficacy against $B$. dendrobatidis. The use of antibiotics and chemotherapeutics against fungal diseases is not a new phenomenon. In previous studies, researchers found minocycline, polymyxin as well as doxycycline to inhibit growth in Candida albicans and Candida tropicalis in vitro [18-20]. Fusarium showed in vitro susceptibility to tobramycin and moxifloxacin [21]. Although trimethoprim in se had no visible effect on in vitro growth of $B$. dendrobatidis, the combination with sulfadiazine resulted in earlier growth arrest, which was clearly visible as impairment of the development of mature sporangia. Both agents thus have a synergistic effect, probably exerted on folic acid synthesis as shown in many prokaryotic taxa [22-24]. Although, the in vitro results obtained with trimethoprim - sulfadiazine might seem promising, not only this combination is not stable in water according to the manufacturer (Kela laboratoria nv, Hoogstraten, Belgium), we also observed acute toxicity in $2 \mathrm{~A}$. muletensis exposed to a concentration of $16 \mu \mathrm{g} / \mathrm{ml}$ of TMP-S (data not shown). Indeed, acute toxicity of TMP-S has been reported for other animal species as well $[25,26]$. We therefore excluded TMP-S from further experiments. Because of the relatively low MIC value, the near absence of toxic effects at a concentration of $10 \mathrm{x}$ the MIC value and its remarkable stability in water, florfenicol was selected for treatment of experimentally infected $A$. muletensis. Although a significant reduction of the number of $B$. dendrobatidis organisms was achieved, the treatment protocol did not eliminate the fungus from its amphibian host, resulting in a rebound effect post treatment. This finding emphasizes the importance of treatments that completely eliminate the fungus from the amphibian host. The reduction in zoospore count in skin samples in florfenicol treated animals found in this study, is similar to that found in the study using chloramphenicol (Bishop et al., 2009). Probably, this is due to the fungistatic activity of florfenicol, resulting only in growth inhibition. Indeed, both florfenicol and the combination trimethoprim sulfadiazine completely killed cultures of $B$. dendrobatidis in vitro at very high concentrations only. Skin defenses in amphibians appear not capable of clearing growth impaired $B$. dendrobatidis cells, which results in recrudescence of the infection after termination of treatment. Another explanation might be poor penetration of florfenicol in the anuran skin. Since clear toxicity symptoms were present in the highest treatment group, sufficient absorption is probably present. However, pharmacokinetic data of florfenicol in amphibians are lacking.

\section{Conclusions}

In conclusion, the use of florfenicol applied in the bath water at 10 and $100 \mu \mathrm{g} / \mathrm{l}$ seems inappropriate to establish chytrid free populations in captivity. Also, the use of higher concentrations of florfenicol can be excluded because of the apparent toxicity at $100 \mu \mathrm{g} / \mathrm{l}$. Further research with individual oral or parenteral treatments of florfenicol, longer treatment regimes and quantification of levels in skin tissue may be interesting, although impractical for treatment of a frog colony. However, since it is mandatory to eliminate $B$. dendrobatidis organisms completely from infected animals, application of voriconazole or itraconazole appears to be the only option at present to reliably control chytridiomycosis in infected amphibians.

\section{Competing interests}

The authors declare that they have no competing interests.

\section{Authors' contributions}

MM carried out the in vitro as well as the in vivo studies, the statistical analyses and drafted the manuscript. AM participated in the design of the study and helped with the interpretation of results. PVR participated in both the in vitro and in vivo studies. KB and PDB carried out the HPLC tests. GV and RD participated in the pathological analyses of the toxicology studies. FV and FH participated in the design of the study and revised the manuscript. FP conceived of the study and participated in its design and coordination and helped to write the manuscript. All authors read and approved the final manuscript.

\section{Acknowledgements}

We would like to thank Dr. J. Longcore, Dr. T. Garner and Dr. M. Fisher for kindly donating five $B$. dendrobatidis strains. This work was funded by a Dehousse grant provided by the Royal Zoological Society of Antwerp to M. Muijsers. 


\section{Author details}

'Department of Pathology, Bacteriology and Avian Diseases, Faculty of Veterinary Medicine, Ghent University, Salisburylaan 133, Merelbeke B-9820, Belgium. ${ }^{2}$ Medicem NV, Industriepark West 68, Sint Niklaas B-9100, Belgium. ${ }^{3}$ Department of Pharmacology, Pharmacy and Toxicology, Faculty of Veterinary Medicine, Ghent University, Salisburylaan 133, Merelbeke B-9820, Belgium. ${ }^{4}$ Royal Zoological Society of Antwerp, Centre for Research and Conservation, Koningin Astridplein 26, Antwerpen B-2018, Belgium.

Received: 19 March 2012 Accepted: 23 August 2012

Published: 25 September 2012

\section{References}

1. Berger $L$, Speare $R$, Daszak $P$, Green $D E$, Cunningham $A A$, Coggin $C L$, Slocombe R, Ragan MA, Hyatt AD, McDonald KR, Hines HB, Lips KR, Marantelli G, Parkess $\mathrm{H}$ : Chytridiomycosis causes amphibian mortality associated with population declines in the rain forests of Australia and Central America. Proc Natl Acad Sci USA 1998, 95:9031-9036.

2. Skeratt LF, Berger L, Speare R, Cashins S, McDonald LR, et al: Spread of chytridiomycosis has caused the rapid global decline and extinction of frogs. EcoHealth 2007, 4:125-134.

3. Longcore JE, Pessier AP, Nichols DK: Batrachochytrium dendrobatidis gen. et sp. nov., a chytrid pathogenic to amphibians. Mycologia 1999, 91(2):219-227.

4. Voyles J, Berger L, Young S, Speare R, Webb R, Warner J, Rudd D, Campbell $\mathrm{R}$, Skerratt LF: Electrolyte depletion and osmotic imbalance in amphibians with chytridiomycosis. Dis Aquat Org 2007, 77:113-118.

5. Voyles J, Young S, Berger L, Campbell C, Voyles WF, Dinudom A, Cook D, Webb R, Alford RA, Skeratt LF, Speare R: Pathogenesis of chytridiomycosis a cause of catastrophic Amphibian declines. Science 2009, 326:582-585.

6. Berger L, Speare R, Pessier A, Voyles J, Skerratt LF: Treatment of chytridiomycosis requires urgent clinical trials. Dis Aquat Org 2010, 92:165-174.

7. Berger L, Speare R, Maranetelli G, Skerratt LF: A zoospore inhibition technique to evaluate the activity of antifungal compounds against Batrachochytrium dendrobatidis and unsuccessful treatment of experimentally infected green tree frog (Litorea caerulea) by fluconazole and benzalkonium chloride. Res Vet Sci 2009, 87(1):106-110.

8. Martel A, van Rooij P, Vercauteren G, Baert K, van Waeyenberghe $L$, de Backer P, Garner T, Ducatelle R, Haesebrouck F, Pasmans F: Developing a safe antifungal treatment protocol to eliminate Batrachochytrium dendrobatidis from amphibians. Medical Mycology 2011, 49(2):143-149.

9. Fisher MC, Garner TWJ, Walker SF: Global emergence of Batrachochytrium dendrobatidis and amphibian chytridiomycosis in space, time and host. Annu Rev Microbiol 2009, 63:291-310.

10. Garner TWJ, Garcia G, Carroll B, Fisher MC: Using itraconazole to clear Batrachochytrium dendrobatidis infection and subsequent depigmentation of Alytes muletensis tadpoles. Dis Aquat Org 2009, 83:257-260

11. Parker JM, Mikaelian I, Hahn N, Diggs HE: Clinical diagnosis and treatment of epidermal chytridiomycosis in African Clawed frogs (Xenopus tropicalis). Comp Med 2002, 52(3):265-268.

12. Hohreiter DW, Rigg DK: Derivation of ambient water quality criteria for formaldehyde. Chemosphere 2001, 45:471-486.

13. Bishop PJ, Speare R, Poulter R, Butler M, Speare BJ, Hyatt A, Olsen V, Haigh A: Elimination of the amphibian chytrid fungus Batrachochytrium dendrobatidis by Archey's frog Leiopelma archeyi. Dis Aquat Org 2009, 84:9-15.

14. Rosenthal RL, Blackman A: Bone-marrow hypoplasia following use of chloramphenicol eye drops. J Am Med Assoc 1965, 191(2):136-137.

15. El-Mofty M, Abdelmeguid N, Sadek I, Essawy A, Abdel-Aleem E: Induction of leukemia in chloramphenicol-treated toads. East Mediterr Health J 2000 6:1026-1034.

16. Pasmans F, Baert K, Martel A, Bousquet-Melou A, Lanckriet R, De Boever S, Van Immerseel F, Eeckhaut V, De Backer P, Haesebrouck F: Induction of the carrier state in pigeons infected with Salmonella enterica subspecies enterica serovar typhimurium PT99 by treatment with florfenicol: a matter of pharmacokinetics. Antimicrob Agents Chemother 2008, 52(3):954-961.

17. Boyle DG, Boyle DB, Olsen V, Morgan JAT, Hyatt AD: Rapid quantitative detection of chytridiomycosis (Batrachochytrium dendrobatidis) in amphibian samples using real-time Taqman PCR assay. Dis Aquat Org 2004, 60:141-148.

18. Waterworth PM: Effect of minocycline on candida albicans. J Clin Pathol 1974, 27(4):269-272.

19. Nicholls MWN: Polymyxin sensitivity of Candida tropicalis. J Med Microbiol 1970, 3:529-538.

20. Lau H, Ballal V, Shenoy S, Acharya SR: Evaluation of antifungal efficacy of $5 \%$ doxycyline hydrochloride, $2.5 \%$ sodium hypochlorite, $17 \%$ ethylenediamine tetraacetic acid and $0.2 \%$ chlorhexidine gluconate against Candida albicans. An in vitro study. Endotontology 2008, 20:6-13.

21. Day S, Lalitha P, Haug S, Fothergill AW, Cevallos V, Vijayakumar R, Prajna NV, Acharya NR, McLeod SD, Lietman TM: Activity of antibiotics against Fusarium and Aspergillus. Br J Ophtalmol 2009, 93:116-119.

22. Bushby SRM, Hitchings GH: Trimethoprim, a sulphonamide potentiator Brit J Pharmacol 1968, 33(1):72-90

23. Bohni E: Chemotherapeutic activity of the combination of trimethoprim and sulfamethoxazole in infections of mice. Postgrad Med J 1969, 45(suppl):18-21.

24. Van Duijkeren E, Van Klingeren B, Vanoldruitenborghoosterbaan MMS, Breukink HJ, Vanniert ASJPAM, Vulto AG: In vitro susceptibility of equine salmonella strains to trimethorpim and sulfonamide alone or in combination. Am J Vet Res 1994, 55(10):1386-1390.

25. Trapanier LA: Idiosyncratic toxicity associated with potentiated sulfonamides in the dog. J of Vet Pharmacol Therap 2004, 27(3):129-138

26. Tjalve $\mathrm{H}$ : Adverse reactions to veterinary drugs reported in Sweden during 1991-1995. J vet Pharmacol Therap 1997, 20:105-110.

doi:10.1186/1746-6148-8-175

Cite this article as: Muijsers et al:: Antibacterial therapeutics for the treatment of chytrid infection in amphibians: Columbus's egg? BMC Veterinary Research 2012 8:175.

\section{Submit your next manuscript to BioMed Central and take full advantage of:}

- Convenient online submission

- Thorough peer review

- No space constraints or color figure charges

- Immediate publication on acceptance

- Inclusion in PubMed, CAS, Scopus and Google Scholar

- Research which is freely available for redistribution 